\title{
Soft Switching of Buck Converter with Coupled Inductor
}

\author{
${ }^{1}$ N.Madhuri, ${ }^{2}$ P.Veera Bhadra Kumari \\ 1,2 Department of Electrical \& Electronics Engineering, Mahatma Gandhi Institute of Technology, \\ Hyderabad, India. ${ }^{1}$ mnerakh @gmail.com, ${ }^{2}$ kumaripvb@gmail.com
}

Abstract - Buck converters are step down dc-dc converters to convert fixed dc voltage to controlled de voltage. Generally, hard switching is used to control de output voltage of buck converter. But this approach leads to high switching losses. In this paper, we propose a Soft Switching of Buck converter with Coupled Inductor, to reduce the switching losses. The circuit configuration has been designed with minimum components for realizing the soft switching. The Simulation of Soft switching of buck converter with coupled inductor circuit has been carried out using MATLAB/SIMULINK and the results obtained.

Keywords- Buck converter, coupled inductort; soft switching, Zero- current switching (ZCS), Zero-voltage switching (ZVS)

\section{INTRODUCTION}

Buck converters are step-down DC-DC converters that are widely being used in different electronic devices like laptops, cell phones and also electric vehicles to obtain different levels of voltage. These converters are nothing but, high frequency switching devices operating on PWM principle. The need for a lighter and smaller, electronic devices propels the need for reduced size of converters operating at higher load currents. With all these unintended conditions the switching frequency has jumped from $\mathrm{KHz}$ range to $\mathrm{MHz}$ range.

The switching devices are made to turn on and turn off the entire load current at high di/dt, and also withstand high voltage stress across them. Due to these two effects there is an increased power losses in these converters and reduces the efficiency significantly. High switching frequency can be used to reduce the size and weight of converters. Still, if converters work under hard-switching conditions, switching losses will rise as switching frequency increases, and the total efficiency will fall down. Soft switching technologies are the best techniques to diminish switching losses, and improve efficiency and reliability. Thus, the size of heat sinks can be reduced. The total weight and size of converters will also be reduced. There are many methods to implement soft switching, and the most common is using extra quasiresonant circuits. By adding auxiliary switches, capacitors and inductors, zero-current-switching (ZCS) conditions or zero voltage switching (ZVS) conditions can be simply achieved in quasi-resonant converters. But, high current stresses and high voltage stresses for power switches are developed. Moreover, in some converters, auxiliary switches work under hard switching conditions producing additional power losses. Due to auxiliary switches, the control technique is more complicated than that of conventional pulse width modulation converters. When the switch is turned off under ZVS condition, due to the small leakage inductance of the coupled inductors, a small voltage spike appears across the switch, and this switch voltage rises slowly to its final value. Thus, even though the voltage spike appears across the switch, the switch is turned off under almost at ZVS condition as the peak vale of the voltage spike is usually much smaller than the maximum switch voltage[1].

The main switch and auxiliary switch operate at ZCS turn-on and turn-off, and all the passive semiconductor devices in the ZCS-PWM converter operate at zero-voltage-switching (ZVS) turn-on and turn-off. Besides operating at constant frequency and with reduced commutation losses, these new converters have no additional current stress in comparison to the hard-switching converter counterpart. The new family of ZCS-PWM converters is suitable for high-power applications using insulated gate bipolar transistors (IGBTs) [4].

An additional winding is added on the same core of the main inductor for the purpose of commutation. By using hysteresis current control, Zero Voltage Switching (ZVS)conditions are ensured over wide load range. The main inductor current is kept in continuous conduction mode (CCM) with small ripple, which allows high output power and small filter parameters. Also, the switching frequency is kept constant when load changes.[5]

An auxiliary circuit which is incorporated in the conventional synchronous buck converter allows power switches to operate with ZVS. Moreover, the reverse recovery problem associated with the body diode of the synchronous switch is solved[6]. The leakage inductance of the coupled inductors can be employed to control the diode current falling rate and to alleviate the diode reverserecovery problem. Then, some soft switching solutions are 
realized by the coupled inductor to reduce the switching losses. Furthermore, the coupled inductor can be operated in transformer mode to avoid the extreme duty cycle and to reduce the current ripple in high step-up or step-down conversion. However, the leakage inductance of the coupled inductors may induce high voltage spikes, which will increase the switch voltage stress, result in serious EMI noise and reduce the system efficiency. [7]

Great amount of research is done to develop soft-switching techniques in dc-dc converters. In these converters, it is desirable to control the output voltage by pulse width modulation (PWM) because of its simplicity and constant frequency. In most of the soft switching converters, efficiency can be improved significantly under heavy load conditions. But, under light load conditions the efficiency is poor due to high power dissipation in the auxiliary circuits.

A new topology using coupled inductor for soft switching of DC- DC buck converter is proposed to solve the low efficiency problem at light load.

\section{PROPOSED TOPOLOGY}

\section{A. ZCS-ZVS Buck converter}

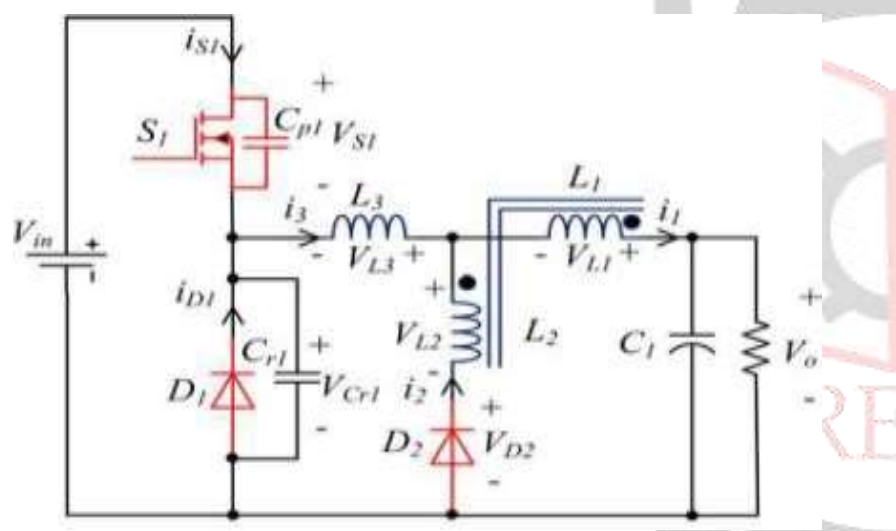

fig 2.1. ZCS- ZVS Buck converter

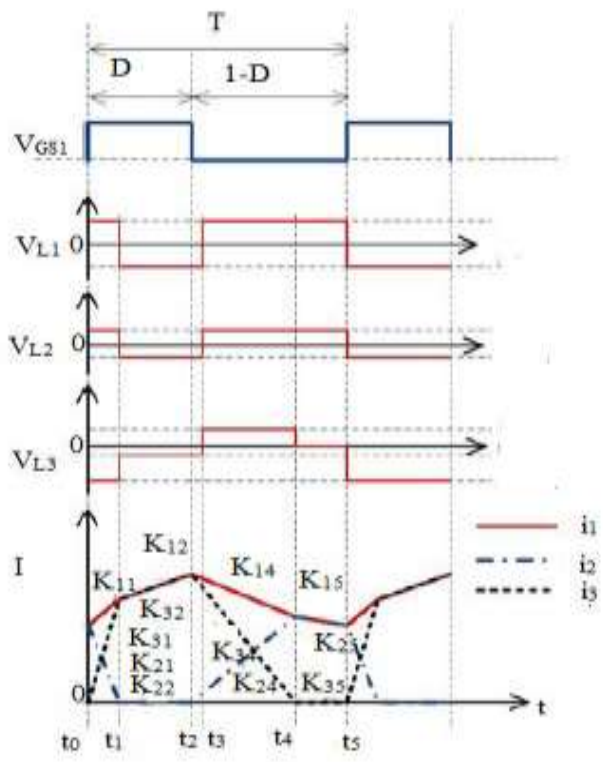

fig 2.2 Theoretical voltage and current Waveforms of inductor
The low-efficiency problem at light loads is mainly due to additional power dissipations of auxiliary circuit branches. Therefore an improved soft switching buck converter with coupled inductor topology is preferred to solve the lowefficiency problems at light loads .In this topology, the auxiliary circuit consists of an inductor coupled with the main inductor, a small inductor as well as a diode. The main MOSFET can operate under a ZCS condition at turn on and a ZVS condition at turn off.

The ZCS-ZVS buck converter topology is shown in fig.1.1. In this topology, inductors $\mathrm{L}_{1}$ and $\mathrm{L}_{2}$ are tightly coupled on the same ferrite core, and $L_{1}$ is the main inductor. $S_{1}$ and $D_{1}$ are the main power switches, like a conventional buck converter. $\mathrm{D}_{2}$ is an additional diode. The theoretical current waveforms of $\mathrm{L}_{1}, \mathrm{~L}_{2}$, and $\mathrm{L}_{3}$ of the proposed converter at steady state are shown in Fig.3.3. When $\mathrm{S}_{1}$ is OFF, the converter comes into a free-wheeling stage. The branches of $\mathrm{L}_{2}$ and $\mathrm{L}_{3}$ will supply two flow channels for current freewheeling. Because $\mathrm{L}_{3}$ is very small, the current of $\mathrm{L}_{3}$ drops faster than that of $\mathrm{L}_{1}$, and also reduces to zero before $S_{1}$ turns ON. It provides the ZCS condition for $S_{1}$. Due to snubber capacitor $\mathrm{Cr}_{1}, \mathrm{~S}_{1}$ can turn OFF under a ZVS condition. $\mathrm{Cp}_{1}$ is the parasitic capacitance of the MOSFET $\mathrm{S}_{1}$. But here no extra auxiliary MOSFET switch is added, so the control method is as simple as that of a conventional buck converter. The theoretical waveforms of inductor currents and voltages are required to analysis the ZCS-ZVS buck converter in steady state.

\section{B. Principle of operation}

Based on the waveforms of the inductor currents.one switching cycle is divided into five intervals, as shown in Fig. 3 , and the equivalent circuits for each interval are given in the section of corresponding modes of operation. Here $\mathrm{K}_{\mathrm{ij}}$ denotes the slopes of inductor current at a different mode, where I denotes the number of the inductor and $\mathrm{j}$ denotes the number of the different operating mode. The detailed theoretical analyses of each mode will be given as follows.

\section{1) Mode $1\left[\mathrm{t} 0-\mathrm{t}_{1}\right]$}

Before $\mathrm{t}_{0}$, the converter works at a current free-wheeling stage, and both $i_{3}$ and is $i_{1}$ are equal to zero. At $t_{0}, S_{1}$ is triggered to conduct. Due to $\mathrm{L}_{3}$, is $\mathrm{i}_{3}$ will increase slowly, so $\mathrm{S}_{1}$ can turn ON under a ZCS condition. Then, $\mathrm{i}_{3}$ and $\mathrm{i}_{1}$ will increase, and $i_{2}$ will go down. Since $L_{3}$ is very small, the current-rising rate of $\mathrm{L}_{3}$ is larger than that of $\mathrm{L}_{1}$. At $t_{1}, \mathrm{i}_{3}$ and $i_{1}$ are equal, and $i_{2}$ is zero. It means that $D_{2}$ turns OFF automatically, and this mode ends. Based on KVL and KCL, we can get

$$
\begin{gathered}
\mathrm{i}_{1=} \mathrm{i}_{2}+\mathrm{i}_{3} \\
\mathrm{VL} 2-\mathrm{VL} 3-\mathrm{Vin}=0 \\
\mathrm{~V} 0-\mathrm{VL} 1-\mathrm{VL} 2=0
\end{gathered}
$$

The voltage equations of inductors $\mathrm{L}_{1}, \mathrm{~L}_{2}$ and $\mathrm{L}_{3}$ can be expressed as follows 
$\mathrm{VL} 1=-\mathrm{L} 1 \frac{\mathrm{di} 1}{\mathrm{dt}}-\mathrm{M} \frac{\mathrm{di} 2}{\mathrm{dt}}$

$\mathrm{VL} 2=-\mathrm{L} 2 \frac{\mathrm{di} 2}{\mathrm{dt}}-\mathrm{M} \frac{\mathrm{di} 1}{\mathrm{dt}}$

$\mathrm{VL} 3=-\mathrm{L} 3 \frac{\mathrm{di} 3}{\mathrm{dt}}-\mathrm{M} \frac{\mathrm{di} 2}{\mathrm{dt}}$

Where $\mathrm{M}$ is the mutual inductance and equal to $\sqrt{(L 1 * L 2)}$

$\mathrm{K}_{11}=\frac{\mathrm{di1}}{\mathrm{dt}}=\frac{\mathrm{VinL} 2}{(\mathrm{~L} 2+\mathrm{M}) \mathrm{L} 3}-\frac{\mathrm{Vo}(\mathrm{L} 3+\mathrm{L} 2)}{\left(\mathrm{L}_{1}+\mathrm{L} 2+2 \mathrm{M}\right) \mathrm{L} 3}$

$\mathrm{K}_{21}=\frac{\mathrm{di} 2}{\mathrm{dt}}=-\frac{\mathrm{VinL} 1}{(\mathrm{~L} 1+\mathrm{M}) \mathrm{L} 3}+\frac{\mathrm{Vo}(\mathrm{M}-\mathrm{L} 3)}{\left(\mathrm{L}_{1}+\mathrm{L} 2+2 \mathrm{M}\right) \mathrm{L} 3}$

$\mathrm{K}_{31}=\frac{\mathrm{di} 3}{\mathrm{dt}}=\frac{\mathrm{Vin}}{\mathrm{L} 3}-\frac{\mathrm{VoL} 2}{(\mathrm{~L} 2+\mathrm{M}) \mathrm{L} 3}$

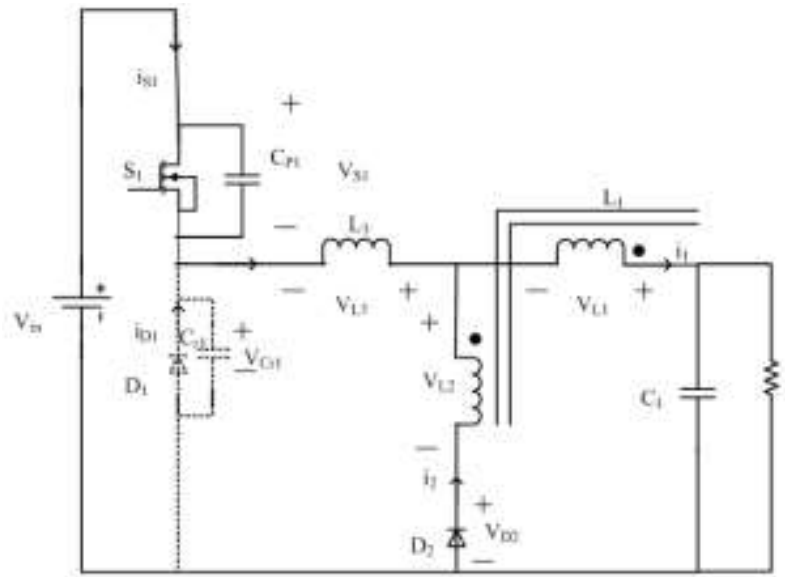

fig. 2.3. Equivalent circuit for mode 1

2) Mode $2\left[t_{1}-t_{2}\right]$

After $t_{1}, i_{3}$ and $i_{1}$ are equal, and both increase linearly. In this mode, $\mathrm{D}_{2}$ is always OFF, and the branch of $\mathrm{L}_{2}$ does not work. At $t_{2}, S_{1}$ turns OFF, and this mode ends. It is similar to that of a conventional buck converter.

The slopes of $i_{1}, i_{2}$, and $i_{3}$

$\mathrm{K}_{12}=\mathrm{K}_{32}=\frac{\text { Vin }-\mathrm{Vo}_{\mathrm{o}}}{\mathrm{L} 2+\mathrm{L} 3}$

$\mathrm{K}_{22}=0$

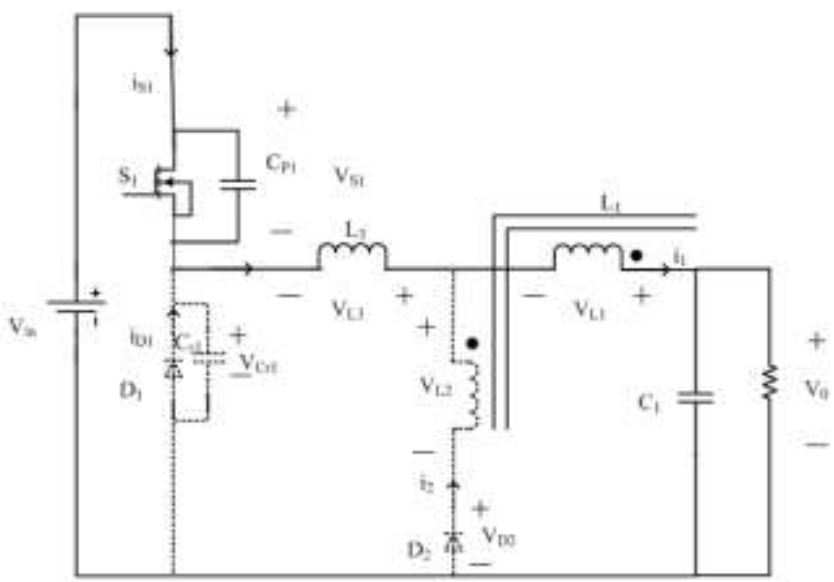

fig.2.4 Equivalent circuit for Mode2

3) Mode $3\left[t_{2}-t_{3}\right]$

At $t_{2}, S_{1}$ turns OFF, and then a resonance occurs between inductors $\left(\mathrm{L}_{1}, \mathrm{~L}_{3}\right)$, parasitic capacitor $\mathrm{Cp}_{1}$, and snubber capacitors $\mathrm{Cr}_{1} . \mathrm{Cp}_{1}$ is charged, and $\mathrm{Cr}_{1}$ is discharged at the same time. When the voltage across $\mathrm{Cr}_{1}$ reduces to zero, $\mathrm{D}_{1}$ will conduct. This interval is very short, so it is assumed that the current in $\mathrm{L}_{3}$ does not change in this mode. Because $C \mathrm{p}_{1}$ is very small, it can be neglected. Thus, the transition time $\mathrm{Tm}_{1}$ can be obtained as follows.

$\mathrm{Tm}_{1}=\mathrm{t}_{3}-\mathrm{t}_{2}=\frac{\text { VinCr } 1}{\mathrm{IL} 3 \mathrm{max}}$

where $I_{L 3}$ max, the value of $i_{3}$ at $t_{2}$ is positive and reaches a maximum in a switching cycle.

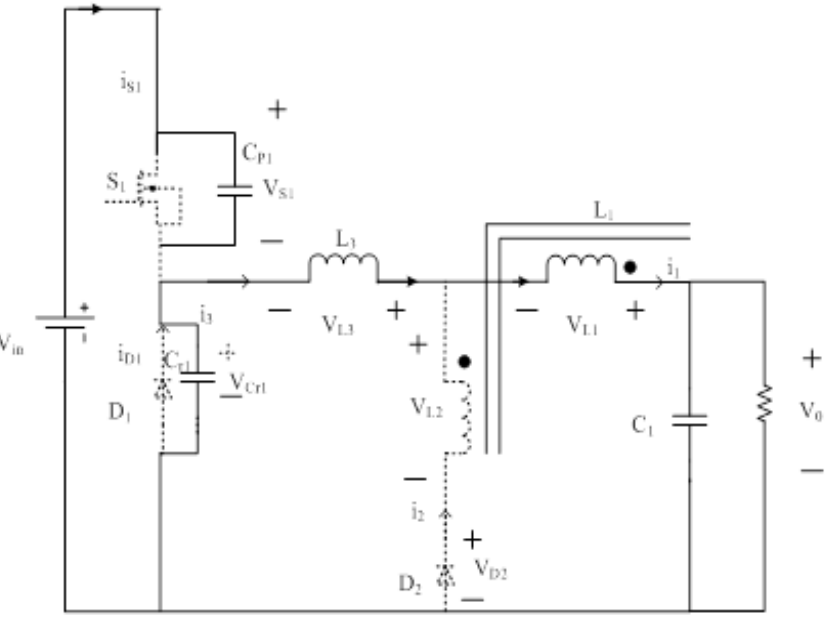

fig.2.5. Equivalent circuit for Mode 3

4) Mode $4\left[\mathrm{t}_{3}-\mathrm{t}_{4}\right]$

When $\mathrm{D}_{1}$ conducts, $\mathrm{D}_{2}$ will conduct simultaneously. The condition that $\mathrm{D}_{2}$ will conduct is shown in the following analyses. Firstly, it is assumed that $\mathrm{D}_{2}$ could not turn $\mathrm{ON}$. The numbers of the turns of $\mathrm{L}_{1}$ and $\mathrm{L}_{2}$ are $\mathrm{n}_{1}$ and $\mathrm{n}_{2}$, respectively, so

$$
\mathrm{V}_{\mathrm{L} 1}=\mathrm{V} 0 \times \frac{\mathrm{L}_{1}}{\mathrm{~L}_{1}+\mathrm{L}_{3}}
$$

Then

$\mathrm{V}_{\mathrm{L} 2}=\frac{\mathrm{n}_{2}}{\mathrm{n}_{1}} \mathrm{VL} 1=\frac{\mathrm{n} 2}{\mathrm{n} 1} \times \mathrm{V} 0 \times \frac{\mathrm{L}_{1}}{\mathrm{~L}_{1}+\mathrm{L}_{3}}=\sqrt{\frac{\mathrm{L}_{2}}{\mathrm{~L}_{1}}} \times \mathrm{V} 0 \times \frac{\mathrm{L}_{1}}{\mathrm{~L}_{1}+\mathrm{L}_{3}}=\frac{\mathrm{V} 0 \mathrm{M}}{\mathrm{L}_{1}+\mathrm{L}_{3}}$

From the KVL equation,we can get

$$
\mathrm{V} 0-\mathrm{VL} 1-\mathrm{VL} 2-\mathrm{VD}=0
$$

Substituting (VL1) and (VL2) into above equation,we can obtain

$$
\mathrm{VD} 2=\mathrm{V} 0 \times \frac{\mathrm{L}_{3}-\mathrm{M}}{\mathrm{L}_{1}+\mathrm{L}_{3}}
$$

If $\mathrm{D}_{2}$ conducts $\mathrm{V}_{\mathrm{D} 2}$ must be less than zero.i.e.,the next inequality must be met $\mathrm{L}_{3}<\mathrm{M}$

After $t_{3}, i_{3}$ will decrease much faster than $i_{1}$ because $L_{3}$ is comparatively small. As long as $\mathrm{i} 3$ reduces to zero, $\mathrm{D}_{1}$ will turn OFF, and the condition of ZCS for $\mathrm{S}_{1}$ is achieved. Then this mode naturally ends. After $\mathrm{D}_{2}$ conducts, $\mathrm{V}_{\mathrm{D} 2}$ is equal to zero.Based on KVL and KCL,we can get

$$
\begin{gathered}
\mathrm{i}_{1=} \mathrm{i}_{2+} \mathrm{i}_{3} \\
\mathrm{VL} 2-\mathrm{VL} 3=0 \\
\mathrm{~V} 0-\mathrm{VL} 1-\mathrm{VL} 3=0
\end{gathered}
$$

Substituting VL1,VL2,VL3 from mode 1 into V0.the current slopes of the inductors are obtained as follows: 123

$$
\mathrm{K}_{14}=\frac{\mathrm{di} 1}{\mathrm{dt}}==-\frac{\mathrm{Vo}(\mathrm{L} 3+\mathrm{L} 2)}{\left(\mathrm{L}_{1}+\mathrm{L} 2+2 \mathrm{M}\right) \mathrm{L} 3}
$$




$$
\begin{aligned}
& \mathrm{K}_{24}=\frac{\mathrm{di} 2}{\mathrm{dt}}=\frac{\mathrm{Vo}(\mathrm{M}-\mathrm{L} 3)}{\left(\mathrm{L}_{1}+\mathrm{L} 2+2 \mathrm{M}\right) \mathrm{L} 3} \\
& \mathrm{~K}_{34}=\frac{\mathrm{di} 3}{\mathrm{dt}}=-\frac{\mathrm{Vo}(\mathrm{L} 2+\mathrm{M})}{\left(\mathrm{L}_{1}+\mathrm{L} 2+2 \mathrm{M}\right) \mathrm{L} 3}
\end{aligned}
$$

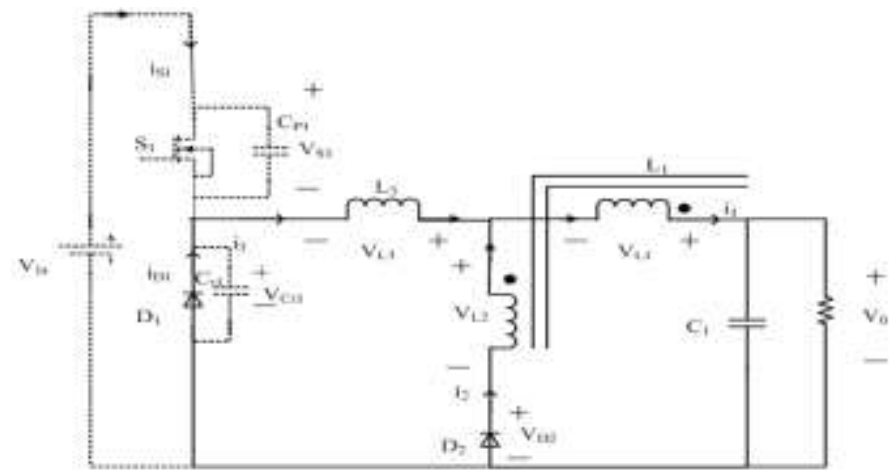

fig.2.6 Equivalent circuit for Mode 4

5) Mode $5\left[t_{4}-t_{5}\right]$

At $t_{4}, D_{4}$ turns $\mathrm{OFF}$, then a small resonance between $\mathrm{L}_{3}$ and $\mathrm{Cr}_{1}$ occurs, in which $\mathrm{i}_{3}$ oscillates around zero and the amplitude is pretty small, so $i_{3}$ is supposed to zero in this mode. Here, the current just flows through $\mathrm{L}_{1}$ and $\mathrm{L}_{2}$, i.e., $\mathrm{i}_{1}$ is equal to $i_{2}$. Therefore, the slopes of $i_{1}, i_{2}$, and $i_{3}$ can be easily obtained as follows:

$$
\begin{aligned}
& \mathrm{K}_{15}=\frac{\mathrm{di} 1}{\mathrm{dt}}=-\frac{\mathrm{Vo}}{(\mathrm{L} 1+\mathrm{L} 2+2 \mathrm{M})} \\
& \mathrm{K}_{25}=\frac{\mathrm{di2}}{\mathrm{dt}}=-\frac{\mathrm{Vo}}{(\mathrm{L} 1+\mathrm{L} 2+2 \mathrm{M})} \\
& \mathrm{K}_{35}=0
\end{aligned}
$$

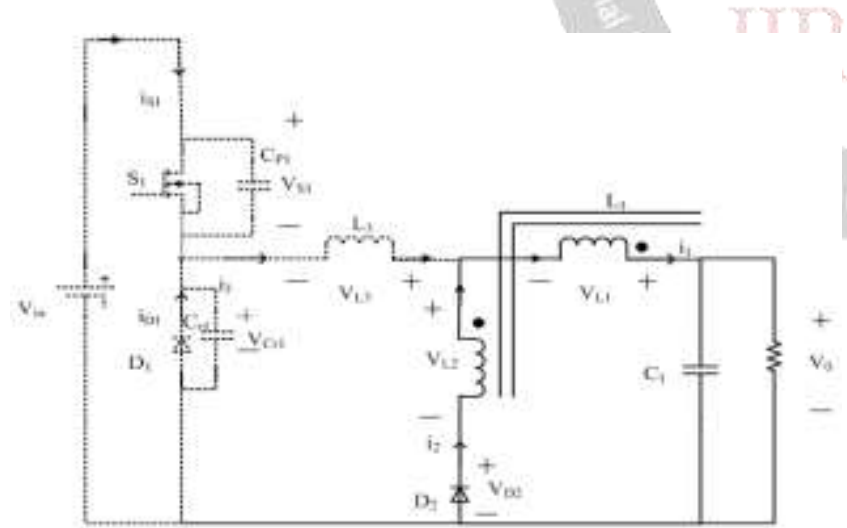

fig.1.7. Equivalent circuit for Mode 5

\section{SIMULATION}

To ensure that the ZCS-ZVS buck converter operates under the soft switching condition, component parameters are designed properly, especially the selection of the inductors(L1,L2 and L3). The current of L3 must be discontinuous to achieve soft-switching conditions. As the load increases, the duration that the current of L3 remains zero will reduce to zero and then L3 will work at a continuous conduction mode(CCM). Thus discontinuous conduction mode(DCM) can be used to calculate the parameters of main circuit

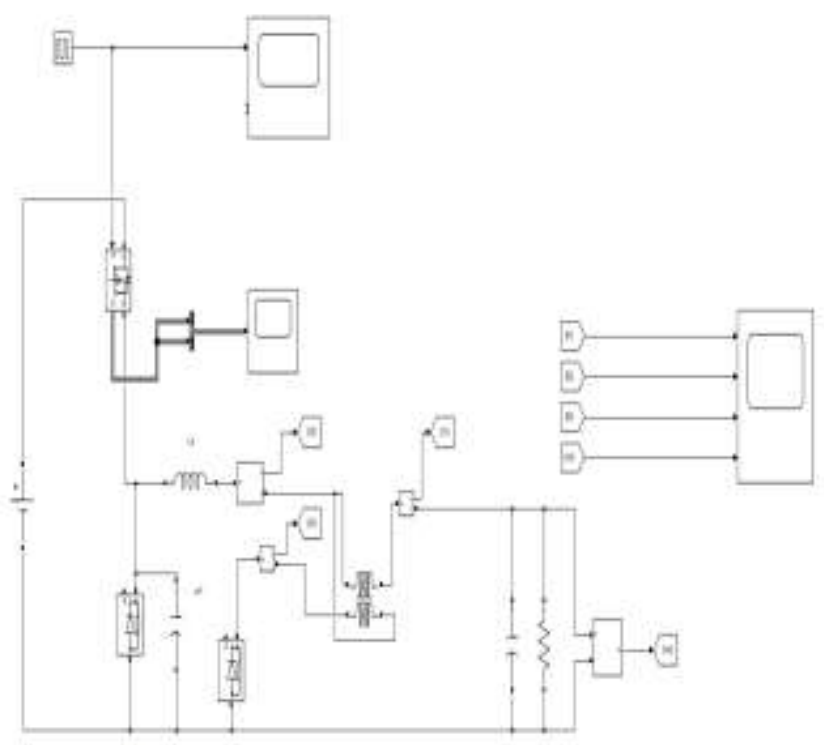

fig 3.1 SIMULINK diagram of ZCS-ZVS buck converter

\section{RESULTS}

Detailed Matlab simulation studies are carried out to verify the circuit, and to predict the performance of the converter The simulation results of Soft switching of buck converter with coupled inductor is shown in table 4.1

\begin{tabular}{|c|c|c|}
\hline Sl. No. & Components & Ratings \\
\hline 1 & DC Source & 70 \\
\hline 2 & Output Voltage & 36 \\
\hline 3 & Inductor $\mathrm{L}_{1}$ & Default value \\
\hline 4 & Inductor $\mathrm{L}_{2}$ & Default value \\
\hline 5 & Inductor $\mathrm{L}_{3}$ & $62.3 \mu \mathrm{H}$ \\
\hline 6 & Output Capacitor $\mathrm{C}_{0}$ & $1000 \mu \mathrm{f}$ \\
\hline 7 & Resistive Load $\mathrm{R}$ & $10.5 \Omega$ \\
\hline
\end{tabular}

Table 4.1 simulation parameters of ZCS-ZVS buck converter 4.2 Observed Waveforms

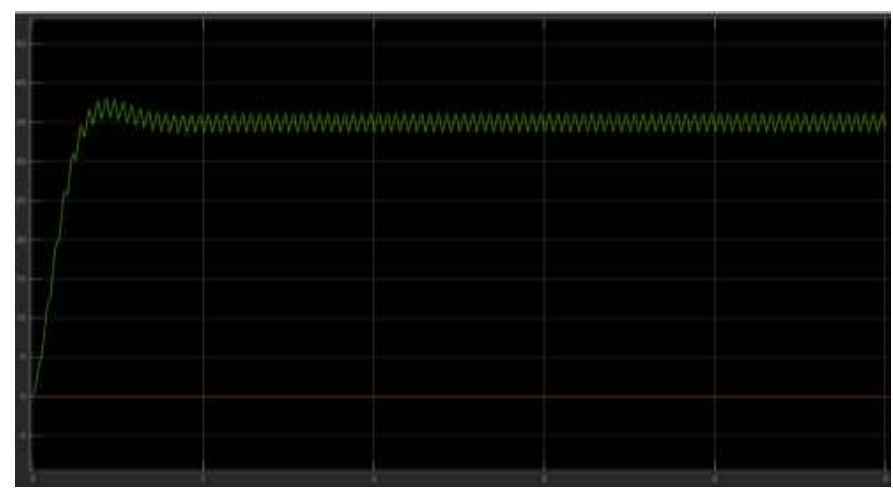

Fig 5.2 Output voltage wave form 
A input voltage of 70 volts is supplied to the circuit and the output voltage observed from the simulation results is 36 volts

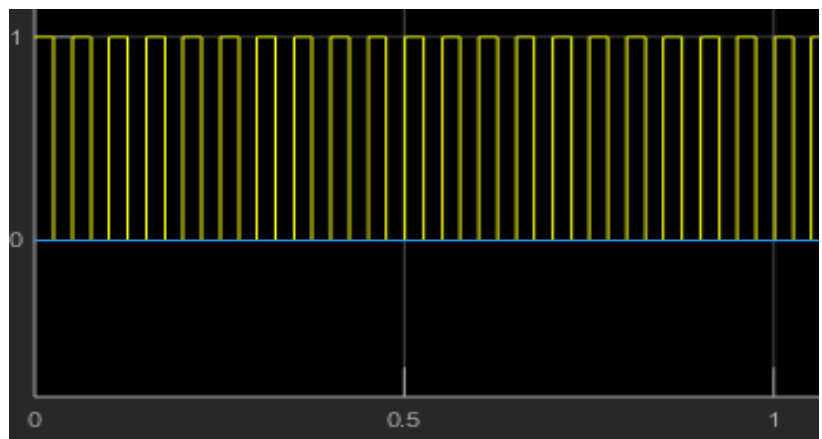

Fig 5.3 Output wave form of pulse generator

A gate pulse for the MOSFET switch is supplied from a pulse generator. and the pulse generator produces a pulse of amplitude 1volt and a duty cycle of $51 \%$ with a switching frequency of $20 \mathrm{kHz}$ which is supplied to the gate terminal of the mosfet

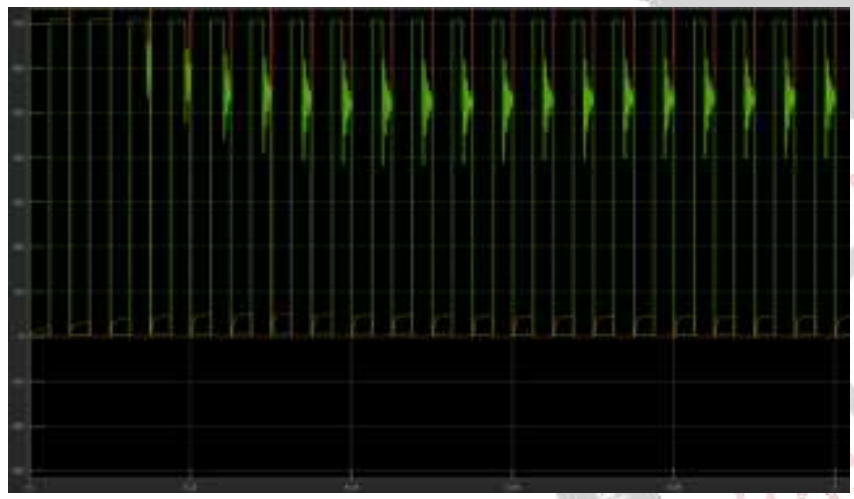

Fig 5.4 voltage waveform across the switch

DC input voltage of 70 volts is applied across the switch and the switch starts conducting if and only if the gate is triggered and the voltage across the switch is 70 volts in turn off condition and 0 volts in turn on condition

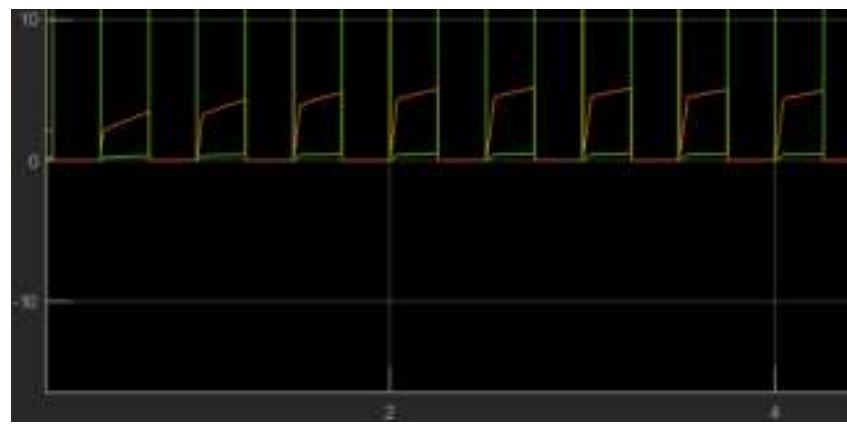

Fig 5.5 Current waveform through the switch

When the gate circuit is fired the switch turns on and the currents starts to flow and reaches the peak value and when the gate pulse is removed the flow of the current decreases to zero from the above wave form it is observed that the overlapping of voltage wave form and current wave form is minimum during turn on and turn off process from that we can infer that the switching losses are minimized.

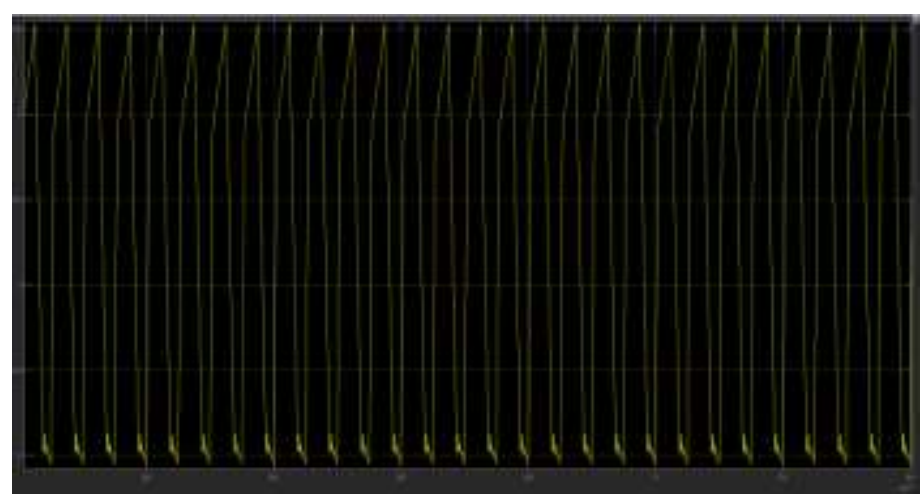

Fig 5.6 Current waveform of inductor $\mathrm{L}_{1}$

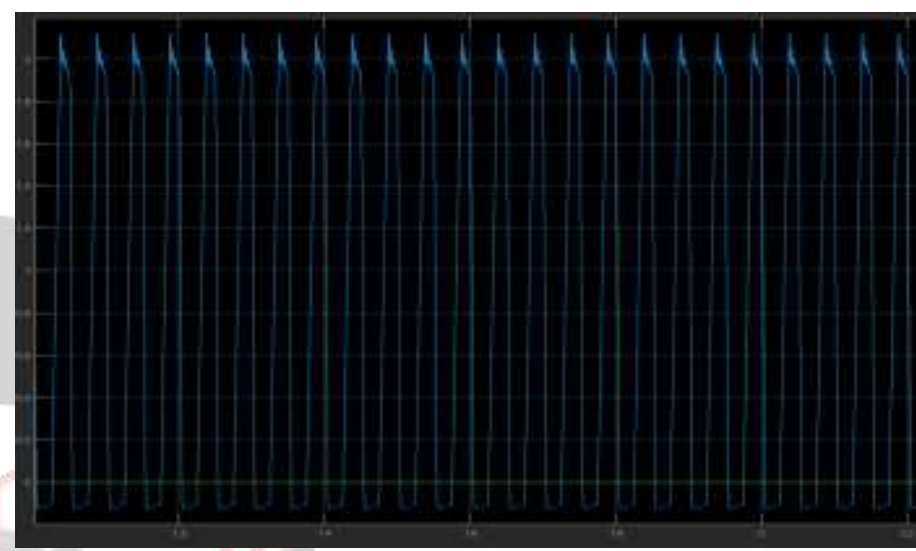

Fig 5.7 Current waveform of inductor $\mathrm{L}_{2}$

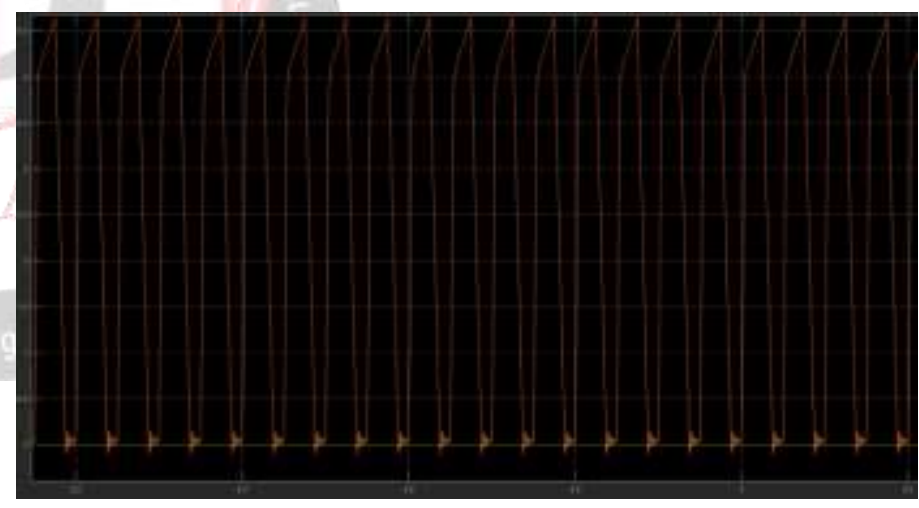

Fig 5.8 Current waveform of inductor $\mathrm{L}_{3}$

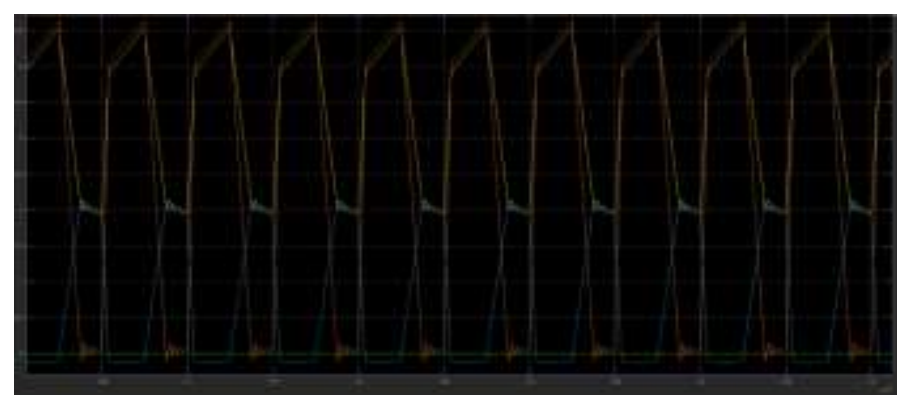

Fig 5.9 Current waveform of inductor $\mathrm{L}_{1}, \mathrm{~L}_{2}, \mathrm{~L}_{3}$

Where Yellow colour line indicates inductor current $\mathrm{L}_{1}$, Blue line indicates inductor current $\mathrm{L}_{2}$, Red line indicates inductor current $\mathrm{L}_{3}$ 


\section{v. CONCLUSION}

Soft Switching of Buck Converter with coupled inductor is simulated using MATLAB/SIMULINK. In this paper, we studied the buck converter using soft switching under two conditions namely (i) zero current switching condition during turn on and (ii) zero voltage switching condition during turn off. It has observed that the proposed converter with soft switching, the efficiency is improved in comparison with conventional switching. Moreover no auxiliary MOSFET is added in this topology, thus the control method is as simple as of conventional buck converter.

\section{REFERENCES}

[1] Reza Amini and HoseinFarzanehfard" Novel Family of PWM Soft-Single-Switched DC-DC Converters With Coupled Inductors" IEEE Trans. on Ind. Electron.,, Vol. 56, No. 6, June 2009

[2] K. Mark Smith and Keyue Ma Smedley "Properties and Synthesis of Passive Lossless Soft-Switching PWM Converters" IEEE Trans. Power Electron., Vol. 14, No. 5, September 1999

[3] E. Adib and H. Farzanehfard, "Family of zerocurrent transition PWM converters," IEEE Trans. Ind. Electron., vol. 55, no. 8, pp. 3055-3063, Aug. 2008

[4] C.-M. Wang, "A new family of zero- current switching (ZCS) PWM converters, "IEEE Trans. Ind. Electron., vol. 52, no. 4, pp. 1117-1125, Aug. 2005.

[5] Y. Zhang and P. C. Sen, "A new soft-switching technique for buck, boost, and buck-boost converters," IEEE Trans. Ind. Appl., vol. 39, no. 6,pp. 1775-1782, Nov./Dec. 2003.

[6] H.-L. Do, "Zero-voltage-switching synchronous buck converter with a coupled inductor," IEEE Trans. Ind. Electron., vol. 58, no. 8, pp. 3440-3447, Aug. 2011.

[7] W. Li, J. Xiao, J. Wu, J. Liu, and X. He, "Application summarization of coupled inductors in DC/DC converters," in Proc. 24th Annu.IEEE Appl. Power Electron. Conf. Expo. , Feb. 15-19, 2009, pp. 1487-1491.

[8] W. Yu, J.-S.Lai, and S.-Y. Park, "An improved zerovoltage switching inverter using two coupled magnetics in one resonant pole," IEEE Trans. Power Electron., vol. 25, no. 4, pp. 952-961, Apr.2010.

[9] Y. Berkovich and B. Axelrod, "Switched-coupled inductor cell for DC-DC converters with very large conversion ratio," IET Power Electron.,vol. 4, no. 3, pp. 309-315, Mar. 2011.

[10] M. R. Mohammadi and H. Farzanehfard, "New family of zero-voltagetransition PWM bi- directional converters with coupled inductors," IEEE Trans. Ind. Electron., vol. 59, no. 2, pp. 912-919, Feb. 2012
[11] C.-T. Tsai and C.-L.Shen, "Interleaved soft-switching buck converter with coupled inductors," in Proc. IEEE Int. Conf. Sustain. Energy Technol., Nov. 24-27, 2008, pp. 877882 .

(1)

